\title{
DE MIDDELEN TOT OPHEFFING VAN SURINAME UIT ZIJN VERVAL.
}

\author{
DOOR
}

S. MULLER VAN VOORST.

\section{I.}

Menigeen zal zich de vraag gesteld hebben: „Waarom blijft Suriname kwijnen, en hadden de herhaalde pogingen in den laatsten tijd gedaan om het tot meerderen bloei te brengen. de zoogenaamde productieve werken als die van het Saramacca-kanaal, de spoorweg naar 't binnenland, de bacovencultuur, de Gouvernementsrubberonderneming, alle zoo weinig succes?" Mijn persoonlijke bekendheid met deze kolonie, waar ik voor bemoeiïngen met cultures bijna twintig jaren grootendeels doorbracht, geeft mij aanleiding daarover 't een en ander in 't midden te brengen.

In de eerste plaats moet ik wijzen op het feit, dat degenen, die geroepen worden om maatregelen tot verbetering van den ongunstigen economischen toestand der kolonie aan te geven, veelal moeten oordeelen na eerst sedert korten tijd en veel te oppervlakkig met het land bekend te zijn, dat voor zooverre het thans bewoonbare gedeelte betreft, als lage, moerassige, tropische kuststrook van een zeer bijzondere gesteldheid is, hetgeen naar mijn meening gewoonlijk teveel uit het oog verloren wordt. Daarbij zijn de bewoners, van welke verscheidene door hun werkkring op de hoogte van bepaalde vraagstukken geacht konden worden, dikwijls aangetast door een zeer sterk tropisch optimisme, niet altijd van een gevoel van slecht begrepen eigenbelang vrij te pleiten, dat hen luchtig over bezwaren doet heen- 
stappen, die zij als ernstig hadden behooren te erkennen. Neemt men bovendien in aanmerking, dat in deze eenigszins afgezonderde kolonie velen zich bevoegd achten, mede te spreken over de algemeene zaak op punten waarop zij het volstrekt niet zijn, vooral wat betreft cultures en hetgeen daarmede in verband staat, dan wordt het begrijpelijk, dat er zeer dikwijls onjuist over Surinaamsche zaken geoordeeld is, en er herhaaldelijk plannen gemaakt zijn, die bij uitvoering op mislukking moesten uitloopen.

Gunstig onderscheidt zich in dit opzicht het belangrijke, uitgewerkte rapport van de studiecommissie van het Suriname Studiesyndicaat, waarvan een résumé in het Februari-nummer (1920) van dit tijdschrift voorkomt. Blijkbaar is dit rapport afkomstig van met tropischen landbouw grondig bekende beoordeelaars, die zich in de kolonie zooveel mogelijk van alles op de hoogte stelden; en waarschijnlijk hebben de talrijke mislukkingen van den laatsten tijd ten slotte het Surinaamsche optimisme ook wel wat getemperd. Verschillende bezwaren, die in vroegere beschouwingen steeds over het hoofd gezien werden, vindt men in dit rapport erkend, al blijkt toch nog op sommige punten het gebrek aan kennis van de kolonie uit eigen ondervinding. Bij de verdere behandeling van mijn onderwerp kom ik op den inhoud hier en daar nader terug.

Ik wees er reeds op, dat het thans bewoonde gedeelte van Suriname door zijn ligging als lage, moerassige tropische kuststrook van een zeer bijzondere gesteldheid is. Deze ligging beneden het hoogwaterpeil van de rivieren en van de zee heeft ten gevolge, dat het land steeds ingepolderd en tegen den overvloedigen regenval op afwatering naar rivier of zee bij laaggetij moet gebracht worden om bewoonbaar en bebouwbaar te zijn; waar geen gelegenheid tot afwatering is, zooals in het bosch dat door de achterdijken van aaneengelegen plantages van de rivier afgesloten wordt, daar staat het in den grooten regentijd zelfs diep onder water. Een uitzondering maken alleen de wat hoogere, be- 
trekkelijk smalle zand- en schulpritsen, die het alluviale land hier en daar, ongeveer evenwijdig aan de zeekust, doorsnijden en op een waarvan Paramaribo is gebouwd; overigens is het zoo vlak dat hoogteverschillen zelfs op grooten afstand niet in meters maar slechts in voeten zijn uit te drukken. Voor den landbouw geven deze bedijking en kanalisatie, vooral bij de dure, ingevoerde arbeidskrachten, natuurlijk zware kosten; wat de bestaande plantages aangaat meestal slechts voor het onderhoud, voor zooverre zij niet door uitbreiding van de inpoldering tot het maken van nieuwe dijken en kanalen genoodzaakt zijn; die onderhoudskosten zijn echter belangrijk, omdat ten gevolge van het afspoelen van grond en het vallen van bladeren in de diepe greppels, waardoor de akkers in bedden verdeeld zijn, deze telkens na eenige jaren opnieuw uitgegraven moeten worden, evenals de trekslooten waarop zij uitloopen en de hoofdkanalen waarop deze laatsten weder uitwateren, en die het water door sluis of looskoker bij laaggetij naar de rivier afvoeren. Bij den hevigen regenval in de natte seizoenen, die gevolgd worden door tijden van dikwijls zeer sterke en langdurige droogte, de schrik vooral van de Surinaamsche cacaoplanters, zooals de vorst dat van de Noord-Amerikaansche sub-tropische vruchtenkweekers is, hangt het welslagen van de cultures in hooge mate af van een drainage tot op voldoende diepte van den zwaren kleigrond waaruit het alluviale land bestaat, en van steeds spoedigen afvoer van het water uit de greppels en liefst ook uit de trekslooten. Van hoeveel gewicht dit is, heb ik in mijn plantersloopbaan voortdurend kunnen opmerken, zoowel door voorbeelden van achteruitgang waar de afwatering onvoldoende was of er een ernstige belemmering in ontstond, als door de geheele verandering, die een verbetering van drainage dikwijls in den stand van de velden en in de productie bracht. Vooral de kosten gaven planters evenwel veelal aanleiding, daaraan niet genoeg aandacht te schenken, en voornamelijk met een te oppervlakkige drainage genoegen te nemen, de 
noodzakelijkheid van die van den ondergrond, subsoil drainage, niet voldoende inziende. Dit had bij de bacovencultuur ook verschil met den vertegenwoordiger van de United Fruit Company ten gevolge, die juist op zeer diepe drainage aandrong, welke niet zoo gemakkelijk spoedig was aan te brengen. Een bezoek aan onze Hollandsche polders, waar tegenwoordig vele landbouwers door kleine windmolens den stand van het water in hun slooten, en daardoor van het grondwater in hun akkers, lager houden dan het algemeene polderpeil, zou in dit opzicht zeer leerzaam voor vele Surinaamsche planters zijn. Bij den kleinen landbouw heerscht deze fout natuurlijk nog in veel grooter mate.

Als een bewijs van den invloed van afwatering in de tropen, zelfs op hoogeren en lichteren grond, herinner ik mij steeds de mededeeling van een suikerplanter op 't eiland Trinidad, waar de cacaocultuur in de bergen en de suikercultuur in het vlakke land aan den voet daarvan gedreven wordt, dat veel grootere opbrengsten van de suikerplantages verkregen werden sedert planters uit Demerary het stelsel van diepe begreppeling hadden ingevoerd. Deze laatsten hechten daaraan terecht steeds groot gewicht voor hun evenals die van Suriname laaggelegen landerijen, en staan ook overigens bekend in West-Indië als goede suikerplanters.

Het is ook opmerkelijk, dat de suikeronderneming van de Nederlandsche Handelmaatschappij in Suriname eerst goede resultaten gaf, toen er planters uit Demerary aan het hoofd gesteld werden, en dat er in geheel Suriname behalve nog één suikerplantage aan Nederlandsche eigenaars toebehoorende verder slechts twee suikerondernemingen zijn overgebleven, beide toebehoorende aan Engelsche eigenaars en bestuurd door planters uit Demerary. Later heeft de Nederlandsche Handelmaatschappij, na den dood van den eersten Engelschen administrateur, een Javaplanter met het beheer belast; doch na korten tijd werd deze weder vervangen door een planter uit Demerary.

Ook een koffieplanter uit Java, wiens onderneming 
aldaar, naar ik meen, door een vulkanische uitbarsting verwoest was, nam gedurende eenigen tijd de leiding van een plantage in Suriname in zijn branche op zich, maar erkende weldra, dat de cultuur in Suriname een geheel verschillende was van die op Java, door de drainage, waarvan hij in 't geheel geen ondervinding had.

Ongetwijfeld heeft minder goede drainage behalve op groei en productie ook grooten invloed op de vatbaarheid der gewassen voor ziekten; en het is volstrekt niet onmogelijk, dat de sterke uitbreiding der nieuwe plagen, die de Surinaamsche cacaocultuur teisteren sedert de krullotenziekte den financieelen toestand der ondernemingen zoo ongunstig heeft gemaakt, voor een deel is te wijten aan den slechten invloed van onvoldoend onderhoud van de bedelvingen, waartoe groote zuinigheid en gebrek aan middelen veelal zullen hebben geleid.

De noodzakelijkheid van afwatering beperkt de geschiktheid voor cultuur van de terreinen in het Surinaamsche laagland evenals in Demerary tot die welke op niet te verren afstand van de rivieren of de zee gelegen zijn. Onjuist is daarom de meening van de Studiecommissie, dat het grondgebruik ten behoeve van den grooten en den kleinen landbouw zich is blijven bepalen tot de strooken langs de rivieroevers tengevolge van het nagenoeg ontbreken van goede wegen. Een plantage van $6000 \mathrm{M}$. diepte van af de rivier behoort reeds tot de uitzonderingen; bij het gebrek aan verval voor de afvoerkanalen in dat geheel vlakke land wordt een voldoend spoedige afwatering in tijden van voortdurenden zwaren regenval op veel grooter afstand onmogelijk. De Nederlandsche Handelmaatschappij, die voor het verkrijgen van genoeg land voor hare suikeronderneming Marienburg aan de Commewijne genoodzaakt was, land tot op verderen afstand van de rivier in te polderen, heeft dan ook daarvoor bovendien afwatering gezocht naar de niet zeer verafgelegen Suriname rivier, waarin de Commewijne uitmondt en waarmede zij een rechten hoek vormt. Dat is natuurlijk slechts 
zelden mogelijk, en bovendien alleen nog uitvoerbaar als er gelegenheid is om daartoe een gedeelte van een andere plantage aan te koopen.

In het geval van de Saramacca-kanaalwerken heeft men getracht, door sluizen te bouwen aan de beide einden van dit tot dien tijd open verbindingskanaal van de Suriname en Saramacca-rivieren, het te verbeteren als vaarwater en het, eerst zelfs zonder inpoldering en afsluiting van de zijstroompjes, tevens geschikt te maken voor de afwatering van het langs de oevers gelegen land, ofschoon de afstand van het midden dezer landstreek naar de sluizen veel grooter was dan bij de het verst van de rivier gelegen plantage-terreinen. Als open water gaf het Saramaccakanaal voor de vaart steeds moeilijkheden, vooral door de ondiepte van het middengedeelte, op de waterscheiding tusschen de twee rivieren, waar in het droge seizoen het bij eb naar beide zijden afstroomende en dan zoute, sterk slibhoudende rivierwater voortdurend ophooging van den bodem veroorzaakte. Daarenboven was het ongeschikt voor afwatering zelfs van afzonderlijk ingepolderde en door looskokers er op spuiende gronden, tenzij op geringen afstand van de toen breede uitmondingen gelegen, omdat de watertoevoer van het omliggende land in den regentijd dikwijls zoo groot is naar dergelijke zijtakken van de hoofdrivieren, dat het niveau, ook tegen laagwater, behalve dicht bij de mondingen, niet genoeg daalt om de bedelvingen der aanliggende gronden daarop uitwatering te kunnen geven. Natuurlijk kan een open kanaal met wijde uitmonding echter veel meer water spuien dan door een zelfs dubbele sluis kan worden doorgelaten, en daar bij het Saramacca-kanaal de hoeveelheid hierdoor opgehouden regenwater veel grooter was in het regenseizoen dan eerst door het zonder de sluizen binnenstroomende vloedwater, maakten deze laatsten zonder inpoldering den toestand veel erger inplaats van beter. De plannen voor deze werken, die een Oost-Indisch ingenieur na een speciaal bezoek daartoe aan de kolonie, had opgemaakt, waren door het 
Koloniaal Bestuur, blijkbaar ten einde lastige en toch waardeloos gerekende critiek te voorkomen, van den beginne af aan alleen ter kennisname voor de leden der Koloniale Staten te hunner griffie gedeponeerd. Schrijver dezes, destijds nog geen lid van genoemd college, maar naar het korte résumé in de pers er van dadelijk vreezende dat het werk geen succes zou zijn, begon een artikel er over, maar liet het liggen wegens onbekendheid met de nadere détails. Toen evenwel jaren later het werk nagenoeg voltooid heette, en de sluizen in werking gesteld zouden worden, voorspelde hij als lid der Staten, en na van de bijzonderheden kennisgenomen te hebben, dadelijk de te wachten teleurstelling. Reeds bij het eerstvolgende regenseizoen werd die dan ook ondervonden. Men besloot toen wel tot inpoldering en afleiding van de zijstroompjes, welke eerst niet noodig waren geacht; maar ten einde ondanks de hooge kosten daarvan het werk toch financieel productief te doen zijn door de pachtopbrengsten der voor den kleinen landbouw uit te geven ronden, nam men boven en behalve het bezwaar van de te groote lengte van het kanaal nog een veel grootere uitgestrektheid binnen de inpoldering dan in verhouding stond tot de capaciteit van kanaal en sluizen voor een voldoende afwatering volgens de ondervinding op de plantages. Het is niet te verwonderen dat deze dan ook niet werd verkregen en het belangrijke werk een mislukking werd.

De Studiecommissie haalt in haar rapport nog aan, dat zij op een harer tochten door het kanaal de huizen der aanwonenden eenige voeten onder water zag staan en van tijdige loozing geen sprake was. Had men bij de inpoldering zich bepaald tot het land aan de uiteinden van het kanaal tot op niet te grooten afstand van de sluizen, en het middengedeelte van het kanaal slechts door indijking tegen het water uit het oningepolderde land beschermd, dan zou het werk wel niet „productief” geweest zijn, maar toch een verbeterde vaart en twee belangrijke, goed afwaterende inpolderingen opgeleverd hebben. 
Van af het aannemen der plannen was wel een planter lid der Koloniale Staten geweest, maar deze had op de bezwaren, welke daartegen te maken waren, niet gewezen. Tegen de autoriteit van een wetenschappelijk deskundige komt menig practicus niet spoedig op, zelfs al kon hij weten, dat eerstgenoemde staat op een voor hem nieuw en eenigszins vreemd terrein; bovendien behoort er, behalve vrij uitgebreide ondervinding van waterkeering en -afvoer in die lage landen met zwaren regenval, ook eenige studie toe om de kennis, daarvan verkregen op het beperkte gebied van plantage-inpolderingen, toe te passen op een werk van zooveel grooter omvang.

De Studiecommissie noemt het kanaal ook als verkeersweg volkomen onvoldoende. Volgens haar zou gebroken moeten worden met de opvatting, het zoowel voor scheepvaart als voor loozing te gebruiken, daar beider belangen te vaak met elkander in strijd komen. Dat zou het geheel opgeven als looskanaal beteekenen, omdat het als vaart naar de Saramacca niet gemist kan worden. Door het de vereischte diepte te geven beneden laagwaterpeil zou men er echter een voldoend vaarwater en looskanaal tevens van kunnen maken; wèl zou het steeds eenigszins een getijvaarwater blijven, daar het gedurende het spuien moeielijk in de richting van een der rivieren af zou kunnen opgevaren worden; maar dat is met alle natuurlijke waterwegen in Suriname ook het geval.

Een nieuw bewijs van gebrek aan inzicht op het gebied van afwatering werd, tot groote verwondering van schrijver dezes, toen reeds niet meer in de kolonie, korten tijd na de teleurstelling bij het in werking komen der Saramaccakanaalsluizen gegeven door het doen graven, iets hoogerop aan de Suriname-rivier, van een klein open kanaal, om perceelen land aldaar op afwatering te brengen, natuurlijk weder zonder succes; en dit niettegenstaande de kritiek in de Koloniale Staten eenige jaren tevoren op een dergelijk plan aan de Saramacca-rivier. 
Evenals in het Saramaccakanaal als open water het niveau veelal niet genoeg daalde in den regentijd om de daaraan gelegen gronden voldoende afwatering te verschaffen, is dit in zekere mate zelfs het geval met de grootere zijtakken der rivieren, waaraan de oude plantages dan ook het eerst verlaten werden en steeds tot de minder belangrijke behoorden. Een uitzondering maakten de kanalen, die van de Beneden Commewijne en de Cottica naar zee liepen, zoolang zij door goede uitwatering op deze laatste den directen invloed van het getij ondergingen; toen echter het ontstaan van modderbanken aan de zeekust de uitwatering begon te belemmeren, werd een goede drainage der aan die kanalen gelegen plantages onmogelijk, behalve in de onmiddelijke nabijheid van de uitmonding der Matappica in de breede Commewijne, waar ook alleen nog plantages zijn overgebleven. Zelfs in de hoofdrivieren daalt in hun smalleren loop, op verderen afstand van de zee, het niveau na grooten regenval somtijds zeer weinig, vooral bij doodgetij; het sterkst is dit natuurlijk het geval als zij een langen benedenloop evenwijdig met de zeekust hebben, zooals de Cottica en Commewijne en vooral de Saramacca. Ik heb op een plantage aan de Cottica herhaaldelijk kunnen zien, hoeveel geringer gelegenheid tot uitwatering de rivier aldaar bood dan op de meer benedenwaarts gelegen plantages; bij doodgetij ontbrak die in den grooten regentijd wel eens geheel. Op een sedert gesloopte kleine suikerplantage aan een nog hoogerop uitmondende zijrivier, de Perica, kon dan somtijds dagenlang niet gespuid worden, hoewel het water hoog in de binnenkanalen der plantage stond. Dit heeft natuurlijk een zeer ongunstigen invloed op de cultures. Toen op genoemde plantage aan de Cottica de afwatering geruimen tijd bovendien nog belemmerd was geweest door onverstandige maatregelen tijdens langdurige afwezigheid van den administrateur, en op dien tijd van overlast van water eerst een zeer zwaar regenseizoen en daarna een felle droge tijd volgden, leed de cacaocultivatie, niettegenstaande 
de radicale verbeteringen, welke dat laatste jaar in de afwatering waren aangebracht en die tot een belangrijke vermeerdering van productie in de volgende jaren leidden, gedurende de droogte zware verliezen, zelfs aan groote boomen, en gaf het eerste jaar daarná bijna geen product.

Tegelijk met de Saramaccakanaalplannen waren er ook andere gemaakt voor betere afwatering van de gronden achter Paramaribo. Ik weet niet in hoeverre die zijn uitgevoerd. Grootendeels liggen deze gronden, evenals de stad zelve, op zand- en schulpritsen, hooger dan de gewone kleigronden zoodat het water daarvan kan afvloeien naar de veelal zeer lage, moerassige gedeelten die er gewoonlijk aan grenzen, en die bij de stad uitwateren door de beken of kreeken en kanalen van de omgeving. De cultuurtuin is daar aangelegd, hetgeen behalve de nabijheid der stad het voordeel moest geven, dat er zoowel zand- als kleigrond aangetroffen wordt. Daar evenwel zandgrond in de kolonie betrekkelijk weinig voorkomt, en de kleigrond daar niet goed op afwatering te brengen is, werd van planterszijde deze keuze van terrein algemeen afgekeurd. Later is door de directie ook op plantage-gronden geëxperimenteerd. Voor veeteelt zijn zulke terreinen geschikt door den lossen, drogen grond en dientengevolge de goede korte, zachte en voedzame grassoorten die zij opleveren. Op den kleigrond is bij minder goede drainage het gras daarentegen zeer spoedig waterachtig, hard en zuur. Die ritsen zijn echter wel uitgestrekt in de lengte, en in sommige streken niet ver van elkaar voorkomend, maar smal, met tusschenliggenden kleigrond. In 't algemeen zijn de terrein-omstandigheden in Suriname dan ook niet zeer gunstig voor veeteelt, waarbij nog komen de plagen van bloedzuigende vleermuizen, insecten, enz. Het is dus zeer verklaarbaar dat, hoewel er ongetwijfeld mooie beesten voorkomen, die het resultaat van goede zorgen zijn, het meeste vee niet te bewonderen valt, en de melkproductie gewoonlijk gering is, en reeds goed gevonden wordt als die zeker nog geen derde be- 
draagt van hetgeen melkkoeien in Holland opleveren.

De terreinen van de afstammelingen der Hollandsche boeren zijn ook achter Paramaribo gelegen. In het rapport der Studiecommissie leest men, dat verbetering van de afwatering daarvan veel tot verhooging van hun nu niet grooten welstand zou kunnen bijdragen; blijkbaar is in dit opzicht dus nog niet veel bereikt. Aanbevolen wordt daarbij, dat door het Gouvernement het noodige worde gedaan voor de verbetering van de hoofdloozingen. Dit geeft mij aanleiding tot de waarschuwing, na alle vroegere mislukkingen op dat gebied eindelijk eens voorgoed in te zien, dat in het lage land van Suriname met zijn zwaren regenval geen waterafvoer resultaten kan geven zonder waterkeering. Waar gelegenheid tot afwatering is of ontstaat, vloeit in den regentijd het water van de geheele omgeving van verren afstand voortdurend heen. Geen drainage van landerijen is er dus mogelijk zonder inpoldering. En daarbij lette men er dan steeds op, dat de uitgestrektheid der ingepolderde landerijen in juiste verhouding staat tot de capaciteit van waterberging gedurende den vloed en het begin van de eb, die de hoofdloozingskanalen bezitten, en tot het vermogen van waterafvoer bij laagwater dat zij met sluis of looskoker hebben; en ten slotte ook daarop, dat bij het geringe verval in het vlakke terrein de afstand naar de uitwateringsboezem niet te groot is, dus bij elk laag getij het water in voldoende mate kan geloosd worden. Bij dit alles moet de practische ondervinding op de plantages tot leiddraad dienen. Theoretisch is dat niet uit te maken, evenals zooveel op ingenieursgebied. Berekent men de hoeveelheid regenwater, die gedurende een zekeren tijd over de oppervlakte van een ingepolderde plantage is gevallen en waarvoor de loozingskanalen ruim voldoende waterberging aanboden, dan ziet men dat een zóó groot gedeelte door opslurping in den grond en door verdamping in de lucht moet zijn opgenomen, dat slechts de praktijk het vereischte vermogen van waterberging en waterafvoer kan aangeven. 
Uit al het voorgaande blijkt wel, dat het niet zoo eenvoudig is als men zonder grondige kennis van de gesteldheid van Suriname wellicht zou meenen, om er voor den kleinen landbouw terreinen geschikt te maken. De eigen vestigingen, voor een groot deel op verlaten plantages, gaven bij het vele werk, noodig voor het in orde brengen en onderhouden van inpoldering en bedelvingen, over het algemeen weinig resultaten. Daarom heeft men hier en daar de zoogenaamde vestigingsplaatsen voor kleine landbouwers ingericht, oude plantages, waar voor bedijking en hoofdloozing van Gouvernementswege wordt gezorgd. Het in orde brengen van die plaatsen kost intusschen steeds veel geld, en oude plantages, waarvan de dijken en de sluizen nog in eenigszins goeden staat verkeeren, worden natuurlijk hoe langer hoe schaarscher; op degenen, die sedert langen tijd verlaten zijn, heeft de zware boschgroei de polderdijken, welke nog niet zijn doorgebroken, dikwijls toch zoo met boomwortels doorboord, dat men ze geheel moet vernieuwen, om ze weder als waterkeeringen dienst te kunnen laten doen; en waar de sluizen onbruikbaar zijn geworden, veroorzaakt het aanbrengen van ijzeren looskokers met de noodige zware beschoeiïngen groote uitgaven.

De bedoeling met die vestigingsplaatsen was, dat er niet alleen gewassen van korten duur werden verbouwd, waarvan de grond slechts gedurende eenige jaren na het vellen van het bosch goede opbrengsten geeft, maar dat onder de schaduw daarvan tevens jonge koffie- of cacaoboompjes opgekweekt werden als blijvende gewassen. Dit is echter voor kleine landbouwers alleen mogelijk bij bepaalden ijver; en slechts in goeden grond, zoodat zij geen gevaar loopen, die blijvende gewassen geruimen tijd te moeten onderhouden, zonder er nog eenig voordeel van beteekenis van te trekken, nadat de voorloopige geen behoorlijke opbrengsten meer geven - de hoofdoorzaak van het kapitaalverslindende van den aanleg van Surinaamsche koffie- en vooral cacaoplantages. $\mathrm{Nu}$ is de vaste kleigrond der oude $\mathrm{Su}-$ 
rinaamsche plantages, die meestal reeds lang in cultuur is geweest, volstrekt niet algemeen zoo vruchtbaar meer als men zonder ondervinding daarvan gewoon is aan te nemen; dit hebben de cacaoplanters herhaaldelijk tot hun groote teleurstelling ondervonden; en langs de rivieren der zoogenaamde oude kolonie, de Suriname, de Commewijne en de Cottica, zijn de landerijen indertijd aanééngesloten als plantagegronden uitgegeven. Vooral oude koffielanden werden vroeger gerekend zeer lang ongebruikt te moeten blijven om weer met eenig succes in cultuur gebracht te kunnen worden; ik las in een oude opgaaf daarvoor zelfs 90 jaar, tegen 60 jaar na katoen- en 30 jaar na suikercultuur; en het is een feit, dat aan den rechteroever van de Cottica, waar de koffieplantages 't langst zijn aangehouden, later de gronden van de kleine landbouwers op die verlaten plantages alle zeer weinig resultaat gaven, terwijl van die aan den linkeroever van die rivier, op de achterlanderijen der oude suikerplantages aan de evenwijdig met de Cottica loopende Boven-Commewijne, verscheidene goed waren.

Aan de Saramacca en aan de nog verder westelijk gelegen Nickerie-rivier, waar meer nieuw land was te krijgen dan aan de rivieren der oude kolonie, hebben zich dan ook later bij voorkeur de kleine landbouwers gevestigd, en met beter gevolg, hoewel zij door de noodzakelijkheid van het maken van geheel nieuwe inpolderingen en afwateringen veelal in dat opzicht zeer onvoldoende werk tot stand brachten, en niet de blijvende resultaten verkregen, die bij den goeden grond anders mogelijk zouden zijn geweest. Deze districten liggen evenwel te ver van het meerendeel der bestaande plantages, aan Suriname en Commewijne, om er vestigingen van kleine landbouwers te stichten met 't oog op het vormen van een bevolking, die arbeidskrachten kan leveren voor den grooten landbouw, zooals in het rapport van de Studiecommissie wordt bedoeld. Daarvoor zouden weder oude plantages in de buurt der bestaande gekozen moeten worden.

In dat rapport wordt gezegd, dat de kleine landbouwer 
de cultuurmethoden van zijn zeer extensief gedreven landbouw zal moeten verbeteren om op de wereldmarkt te kunnen concurreeren ook bij lager marktprijzen dan de tegenwoordige exceptioneel hooge. Ik geloof echter, dat men daarvan geen groote verwachtingen moet koesteren, vooral bij den aard van den gewonen tropischen kleinen landbouwer; hij heeft in Suriname reeds veel werk aan het schoonhouden van zijn grond door den snellen groei van het gras op dien lagen kleibodem, en aan het in orde houden van de bedelvingen in zijn akkers; door de noodzakelijke verdeeling daarvan in zijwaarts eenigszins afloopende bedden wordt ploegen hem ondoenlijk gemaakt, nog daargelaten de belemmering door boomwortels en stronken in nieuw-ontgonnen land, en buitendien ontbreekt trekvee; eveneens ook stalmest. Op de mogelijkheid van concurreeren met goedkooper werkende landen met hoogeren, lichteren grond zal dus niet zoo sterk gerekend mogen worden.

Een cultuur, die niet de eischen van inpoldering en drainage stelt als de gewone landbouw, is die van rijst, waarvoor het onderwater staan van het land in den regentijd zelfs noodig is; de Surinaamsche rijst is daarenboven van een zeer goede qualiteit. Geruimen tijd geleden zijn Britsch-Indische immigranten, die zich na afloop hunner plantage-contracten als kleine landbouwers hadden gevestigd, op beperkte schaal op slecht afwaterende terreinen met deze cultuur begonnen, die daarvóór nog slechts in 't klein door de boschnegers gedreven werd in het binnenland. Het is niet te verwonderen, dat er gedurende den oorlog een groote uitbreiding aan werd gegeven door de belemmering van den invoer van buitenlandsche rijst, en pelmolens werden opgericht. Het komt mij voor, dat deze cultuur in Suriname voor den kleinen landbouw zeker toekomst heeft, vooral bij betere toepassing van irrigatie uit de moerassen, zooals de Studiecommissie bepleit.

Ik geloof intusschen nog steeds hetgeen ik reeds een dertigtal jaren geleden, in den eersten tijd van mijn verblijf in de kolonie, in een tweetal artikelen in „de 
Gids" (Apr. 1887 en Mrt. 1890) uiteenzette, dat de groote landbouw altijd voornamelijk de productie van Suriname zal moeten blijven geven; en daar ik thans directe noch indirecte belangen meer in de kolonie heb, oordeel ik nu zeker wel van een geheel onpartijdig standpunt. De groote landbouw heeft in Suriname stellig in de eerste plaats behoefte aan invoer van werkkrachten. De Studiecommissie beschouwt mijns inziens dus zeer terecht maatregelen daartoe als een hoofdzaak voor de opheffing der kolonie uit haar staat van verval. Ook volkomen juist acht ik de meening, dat voor de immigranten de groote landbouw de goede en eenige leerschool is om hen voor te bereiden tot zelfstandig werken als kleine landbouwers; dit is zeker vooral met 't oog op de bodemgesteldheid van Suriname zeer waar. Ik vrees echter dat, zelfs als behalve voor den grooten landbouw ook voor andere industrieën en Gouvernementswerken arbeiders worden aangevraagd, en de contracten van vijfjarige tot driejarige verkort worden, moeielijk binnen niet te langen tijd 100.000 immigranten aangevoerd zullen kunnen worden, zonder welk aantal de Studiecommissie meent dat de kolonie niet financieäl onafhankelijk te maken zou zijn; toen de immigratie onbelemmerd plaats had stelden de gezamelijke plantages geen vijfde gedeelte van dat aantal tewerk en werden er jaarlijks ook slechts een paar duizend immigranten aangevoerd. Na hetgeen ik over de inrichting van vestigingsplaatsen voor kleine landbouwers reeds in het midden bracht, behoeft het geen betoog, dat het beschikbaar stellen daarvan voor een zeer groot aantal immigranten na afloop van hun contracten bovendien in elk geval niet licht geteld mag worden.

Intusschen is het niet tegen te spreken, dat slechts een zeer groote bevolking van kleine landbouwers van veel beteekenis zou zijn voor het verschaffen van werkkrachten aan de plantages, die niet alleen langs verschillende rivieren over groote afstanden verspreid liggen, maar buitendien voor het omvangrijke werk aan onderhoud, dat velden en bedelvingen in den Surinaamschen 
384 DE MIDDELEN TOT OPHEFFING VAN SURINAME.

lagen grond vereischen, in het juiste seizoen op de daarvoor noodige arbeiders moeten kunnen rekenen. Het delfwerk in de velden kan slechts in het regenseizoen gedaan worden, daar de grond er anders veel te hard voor is; het uitdelven van de hoofdkanalen is een werk voor den drogen tijd, omdat zij dan eerst zonder teveel water zijn en niet noodig voor de afwatering der plantages. De regentijd is tevens het seizoen voor het planten en bijv. op cacaoplantages voor den pluk, terwijl dan door den sterken groei van het gras ook het meeste wiedwerk valt te doen. Natuurlijk hebben in dien tijd de kleine landbouwers ook het meeste werk in hun gronden. Ik blijf daarom bij de meening, reeds in mijn genoemde Gidsartikelen uitgesproken, dat het meerendeel der plantages een vaste arbeidsmacht toch nooit geheel zullen kunnen ontberen, die alleen door contractanten geleverd worden kan, daar zelfs op het werk van op de onderneming gevestigde vrije arbeiders, door het bezit van een grondje eenigszins aan haar verbonden, niet voldoende is staat te maken. Het schijnt dat in Demerary het ophouden van de immigratie uit BritschIndië onder contract dan ook een groote ontsteltenis onder de planters teweeggebracht heeft, niettegenstaande de talrijke bevolking van vrije immigranten die daar aanwezig is.

De Javanen blijken, hoewel men vroeger aan hun geschiktheid meende te moeten twijfelen, op den duur als arbeiders goed te voldoen; bovendien schijnen zij voor den kleinen landbouw nog meer aanleg te bezitten dan de Britsch-Indiërs. De voortzetting van deze immigratie op ruime schaal is zeker dan ook onontbeerlijk voor de kolonie; en tevens in het belang van de immigranten zelf. Op de negerbevolking kan men als landbouwarbeiders niet rekenen, zooals de ondervinding ook in Demerary en elders geleerd heeft. Later heeft het Afrikaansche element ook getoond voor den kleinen landbouw veel minder geschiktheid te bezitten dan voor ambachten en andere bedrijven, waarop door de Studiecommissie eveneens wordt gewezen.

(Slot volgt). 